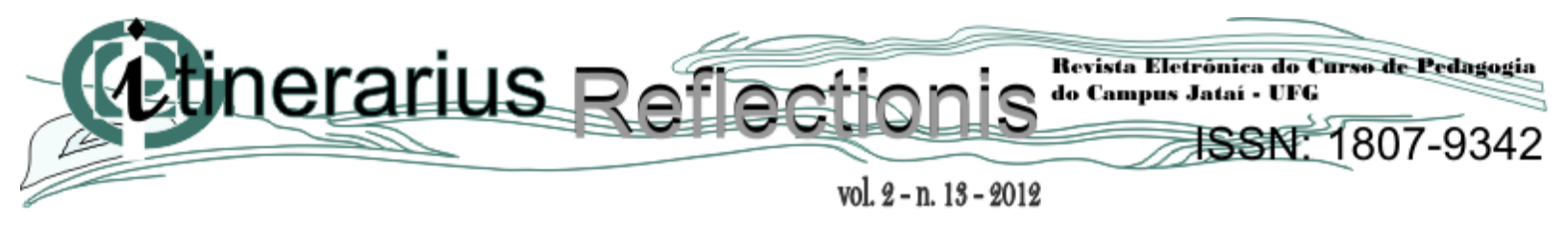

\title{
UMA ANÁLISE DOS CURSOS DE LICENCIATURA EM FÍSICA NO IFG/CAMPUS JATAÍ E UFG/CAMPUS JATAÍ
}

\author{
Daniela Furtado Campos - IFG/Campus Jataí \\ daninhafurtado1@yahoo.com.br
}

Luciene Lima de Assis Pires - IFG/Campus Jataí lucieneapires@gmail.com

\begin{abstract}
RESUMO: No presente artigo analisa-se os cursos de Licenciatura em Física ofertados na cidade de Jataí-GO pelo Instituto Federal de Educação, Ciência e Tecnologia de Goiás (IFG) Câmpus Jataí e Universidade Federal de Goiás (UFG) Campus Jataí, indicando divergências e convergências. A metodologia utilizada foi a pesquisa bibliográfica e documental; analisou-se as matrizes curriculares dos dois cursos tendo como base teórica dentre outros autores Barone (2008), Queiroz (2001), Santana et al (2005), Mion (2008). Verificou-se que as matrizes curriculares são semelhantes, que as horas destinadas às disciplinas pedagógicas e às disciplinas específicas da Física são bem próximas, com diferença de poucas horas, mesmo assim elas formam professores e não bacharéis, visto que a carga horária está em conformidade com a legislação para formação de professores.
\end{abstract}

Palavras-chave: Formação de professores. Licenciatura em Física. Currículo.

\begin{abstract}
This paper analyses the Physics courses offered in the city of Jatai-GO by Instituto Federal de Educação, Ciência e Tecnologia de Jataí-Goias (IFG) and Universidade Federal de Goiás (UFG), indicating convergences and divergences. The methodology was based on a documental and bibliographical research; It was analyzed the curriculum of both courses and theoretical basis was Barone (2008), Queiroz (2001), Santana et al. (2005), Mion (2008), and other authors. It was found that the curricula are similar; the number of hours for pedagogic disciplines and for specific Physics disciplines are very close. However, even presenting a very slight difference of hours, both IFG and UFG graduate teachers, not bachelors, since the hour load is according to the legislation for teachers formation.
\end{abstract}

Key-words: Teacher training. Degree in Physics. Curriculum.

\section{Considerações iniciais}

A formação de professores de Física no Brasil é bastante comentada, sendo tema de 


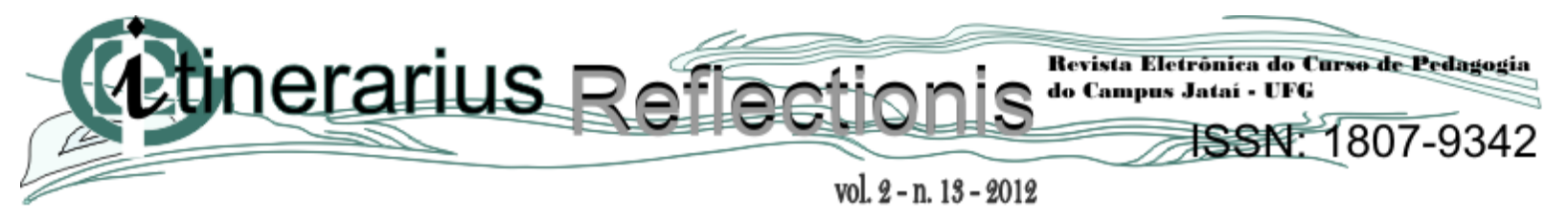

vários seminários e encontros promovidos pela Sociedade Brasileira de Física $(\mathrm{SBF})^{1}$ (MACHADO, 2009). Nesses encontros demonstra-se a grande insatisfação com a formação dos professores, ou seja, como eles são preparados nas universidades do país e quais os caminhos a seguir.

Na realidade, o problema da formação docente vem desde o descobrimento do Brasil (MACHADO, 2009). A escola em si, surgiu com a chegada dos Jesuítas, por volta de 1570; período em que foi implantada uma elitização do ensino; pois os negros e índios iam para os campos, enquanto os filhos da elite iam para a escola para serem preparados para o trabalho intelectual. Merece destaque neste período inicial as leis orgânicas do ensino secundário, a Lei de Diretrizes e Bases (LDB) de 1961. Segundo Machado (2009), em 1968 foi aprovada a lei que "fixou a organização e as normas de funcionamento do ensino superior e sua articulação com a escola média", Lei 5.540/1968. Em 1971 aprovou-se a LDB 5.692, com ela, a reestruturação dos ensinos de $1^{\circ}$ e $2^{\circ}$ graus e a exigência de uma formação mínima para o exercício do magistério. No entanto, contraditoriamente, a própria lei que exigia a formação mínima permitia a presença do leigo na sala de aula, no artigo 78; e, dentre eles, o professor de Física, o que potencializou a situação que perdura nesta primeira década do século XXI, qual seja a falta maciça professores para a educação básica para as disciplinas de Física, Química e Matemática. Segundo dados do Inep (2009), em 2009 havia um déficit de 55 mil professores de Física no país.

Segundo Pereira (1999), são vários os fatores externos ao processo pedagógico que prejudicam a formação inicial e continuada dos professores no país; inclusive servindo de desestímulo aos jovens para se tornarem professores; isto é resultado das más condições de trabalho, dos salários pouco atraentes, da jornada de trabalho excessiva e em alguns casos a falta de planos de carreira.

Iniciamos a segunda década do século XXI e o ensino de Física está baseado em

\footnotetext{
${ }^{1}$ EPEF (Encontro de Pesquisa em Ensino de Física) e o SNEF (Simpósio Nacional de Ensino de Física), o ENPEC (Encontro Nacional de Pesquisadores em Educação em Ciências) produzido pela ABRAPEC (Associação Brasileira de Pesquisa em Educação em Ciências) e além de outros eventos regionais.
} 


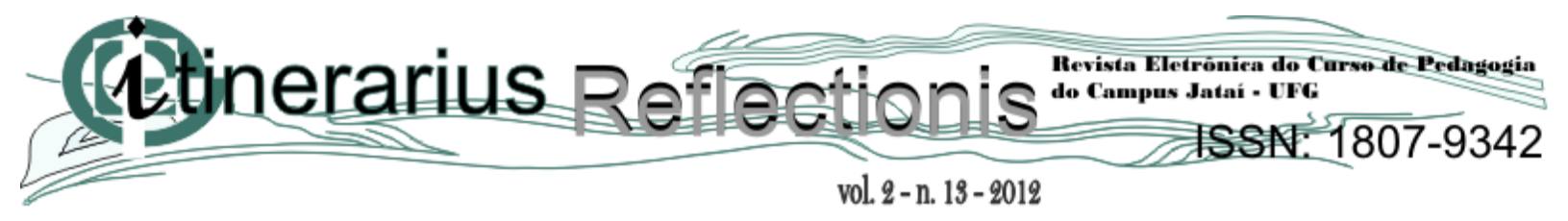

procedimentos tradicionais: escola, professor e aluno. Para Tricárico (1989), eles formam uma orientação para o grupo de receptores do processo, no qual os alunos apenas recebem o conteúdo e não participam da sua construção. E quando o resultado das avaliações é apresentado já é tarde para uma mudança de conceito. $\mathrm{O}$ autor afirma ainda que para que essa realidade seja diferente é necessário que os docentes tenham liberdade para inovar e criar situações de acordo com o material disponível e a comunidade assistida. Os futuros professores devem desenvolver sua inteligência e personalidade com relação ao ensino-aprendizagem dos seus alunos e não simplesmente reproduzirem conhecimentos pré-fabricados.

Também analisando a formação de professores no Brasil, Scheibe (2008) afirma que é necessário que se compreenda que a escola é uma instância social que tem como missão a organização do pensamento de novas gerações, isso é fundamental na trajetória da formação dos profissionais da educação. Seguindo o pensamento de Scheibe (2008), a construção de um sistema nacional de formação dos profissionais da educação nos mostra e exige o desafio da análise cuidadosa e atenta das mudanças e ações previstas para o futuro da formação.

A função da escola não é apenas reproduzir o conhecimento que existe e uma cultura considerada única (LEITE, 2006, p. 281); admite-se que a formação de professores tem que ir além do acúmulo de conhecimentos e do domínio das disciplinas para que a educação escolar possa ser inclusiva e formadora de opinião, trazendo valores para uma sociedade mais justa e democrática. Para esta autora, exige-se dos professores a capacidade de estabelecer uma ligação entre o pensar, enquadrando as situações, o decidir, frente a opções possíveis, e o agir; buscando fortalecer a relação teoria-prática.

Nesse contexto, é interessante destacar, a importância da teoria crítica e no contexto da formação de professores de Física, a proposta de Mion (2008), afirmando que o conhecimento construído guardado em teorias, remete a uma teoria e prática e a inter-relação entre ambas. Para a autora, a teoria crítica não trata separadamente teoria e prática; e sim busca a interação entre as duas, assumindo assim compromisso com a transformação social.

O objetivo da teoria crítica é elaborar propostas educacionais que promovam a 


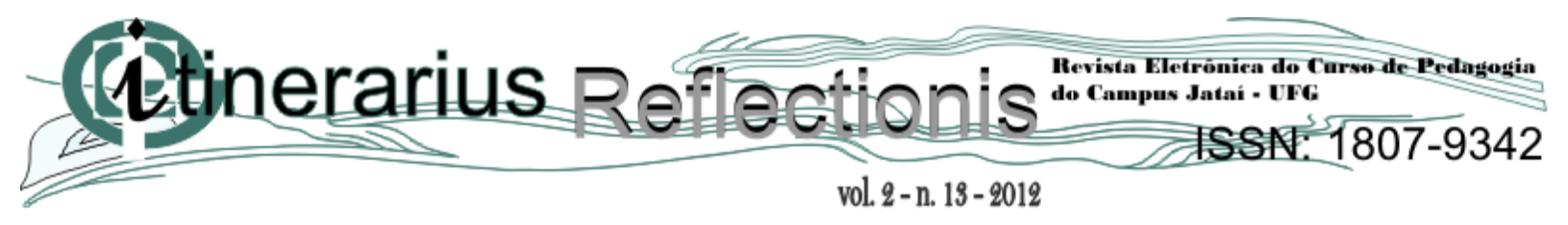

interação entre teoria e prática na construção de conhecimentos científico-educacionais, buscando avançar na construção da cidadania, debatendo as relações entre ciência, tecnologia e sociedade.

A proposta educacional da teoria crítica é vivenciar as pesquisas e não somente coletar os dados, pois os professores devem ser os construtores de suas próprias propostas educacionais, visando à vivência da investigação-ação na educação para formar alunos de Ensino Médio com a compreensão da Física e ampliando sua visão de mundo e a sua percepção crítica (MION, 2008). Partindo desse pensamento que as instituições formadoras deveriam seguir é que tem início a pesquisa envolvendo os cursos de licenciatura em Física na cidade de Jataí.

No município de Jataí, estado de Goiás, com 80 mil habitantes, é ofertado dois cursos de Licenciatura em Física: um no Instituto Federal de Educação, Ciência e Tecnologia de Goiás (IFG) e outro na Universidade Federal de Goiás (UFG). O curso do IFG teve início no ano de 2001 como Licenciatura em Ciências com habilitação em Física e em Matemática, no ano de 2003 passou-se a ofertar somente a habilitação em Física e o curso passou a ser denominado de Licenciatura em Física. O curso da UFG teve início no segundo semestre de 2006.

Após o início do curso na UFG, havia comparações entre as graduações em Física das duas instituições, sendo a Licenciatura do IFG com grande carga horária pedagógica e sem aprofundamento nos conteúdos relacionados à Física, formando basicamente professores para atuarem no Ensino Médio, e a Licenciatura da UFG com grande carga horária e com aprofundamento em disciplinas de Física em detrimento das disciplinas pedagógicas, formando bacharéis com diplomas de licenciatura.

Esta situação foi assim considerada objeto de estudo desta pesquisa: analisar em que condições esses cursos são ofertados, comparar as matrizes curriculares dos dois cursos em análise verificando semelhanças e diferenças na oferta das disciplinas, nas ementas e referencial bibliográfico a fim de compreender se os comentários e as comparações feitas têm fundamento real ou são apenas conjecturas de senso comum.

A pesquisa tem como base metodológica a análise documental e bibliográfica. A pesquisa bibliográfica segundo Sá-Silva (2009) é um modo de estudo que analisa documentos 


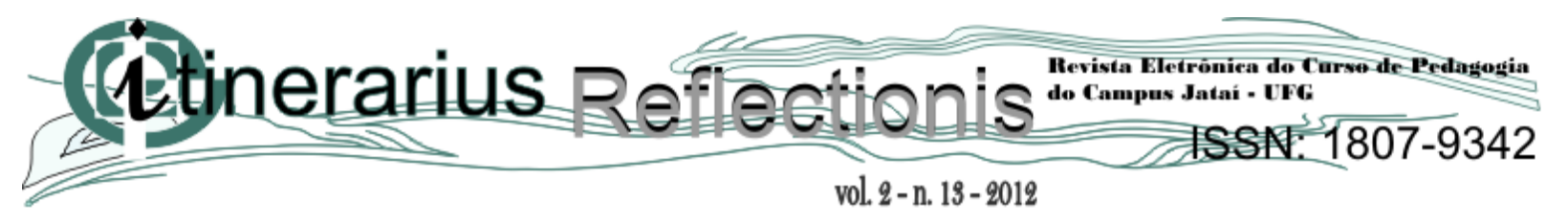

chamados científicos, pois o pesquisador tem a certeza de que tais documentos foram estudados e são confiáveis. A análise dos documentos teve como base a análise de conteúdo proposta por Bardin (1977) que serviu também como base para a análise das matrizes curriculares dos cursos. A pesquisa documental se caracteriza, conforme salienta Sá-Silva (2009) pelas informações sem tratamentos científicos e que não foram divulgadas.

Partindo do que institui a legislação sobre a formação de professores no Brasil e, em particular a formação de professores de Física, inicialmente analisou-se os projetos pedagógicos dos cursos (PPC) dos cursos de Licenciatura em Física do IFG/Campus Jataí e da UFG/Campus Jataí, comparando-os. Em seguida analisaram-se as matrizes curriculares e as disciplinas estabelecendo comparação entre as denominações, verificando carga horária, ementa e bibliografia. Os resultados são apresentados a seguir.

\section{Formação de professores}

Existem poucos formados em Licenciatura em Física no Brasil (BARONE, 2008). Segundo o autor, para muitas pessoas a licenciatura é vista como um subproduto do bacharelado em Física, formando uma grande disputa entre licenciados e bacharéis em relação ao conhecimento das disciplinas específicas. Para agravar ainda mais o quadro da formação do professor de Física, existe a política para permissão do bacharel em sala de aula com um curso básico de disciplinas pedagógicas. Ainda existe a ideia de formação de um profissional polivalente para suprir a falta de professores qualificados em sala de aula (BARONE, 2008).

Para Borges (2006) a sociedade exige que os professores formem seus filhos para a vida, porém, exige que os formem para passar no vestibular, gerando um ensino propedêutico. Contudo, a formação do professor não pode variar conforme o humor do mercado.

No entanto, os cursos de formação buscam novos caminhos, novos currículos, nos quais o aluno é levado a pensar cientificamente e criticamente, a ciência evoluiu, mas o ensino de Ciências não. O professor repete com seus alunos o modelo aprendido na faculdade: 


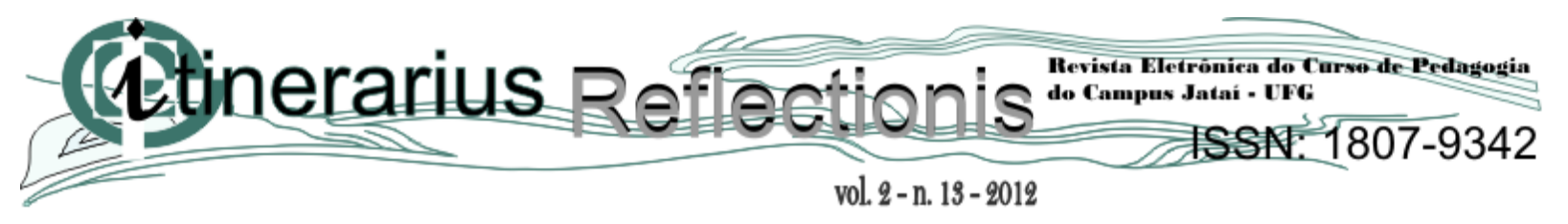

memorização de fórmulas e resolução de exercícios (BORGES, 2006).

No que diz respeito ao ensino de Física, Borges (2006) diz que existe o problema de como os conteúdos são apresentados, então se pode fazer na graduação a apresentação das teorias com os mesmos rigores que são exigidos em experiências, juntando teoria e pedagogia. Devem-se levar os alunos a desenvolverem aprendizagens múltiplas para que sejam capazes de pensar e resolver situações que dependam dos outros e com isto aprendam com a interação entre as pessoas. Ainda para este autor, os professores universitários devem ler mais e se inteirarem mais sobre as pesquisas pedagógicas. Não resistirem e sim melhorarem as suas práticas e terem paixão no que fazem. Queiroz (2001) faz considerações sobre o que gera a formação do professor no seu dia a dia ao dizer que:

$\mathrm{O}$ 'saber da experiência' precisa ser analisado em sentido profissional amplo, de modo a fazer emergir a relação entre a formação docente e as diversas interferências, tais como: da escolarização; das leituras sobre pesquisas em educação em geral e em educação em Ciências em especial; das participações em pesquisas educacionais acadêmicas ou na escola; dos cursos de atualizações e pós-graduação que realizaram; dos seminários, encontros, conferências e palestras que assistiram e das trocas realizadas tanto com colegas na escola como com professores dos diferentes níveis de ensino (QUEIROZ, 2001, p. 99).

E toda essa troca começa no estágio supervisionado, onde, oficialmente, se dá o primeiro contato do futuro professor com a sala de aula, já que é sabido que os professores são influenciados por seus mestres e assim já possuem o primeiro contato com a profissão, mesmo sem ter chegado na sala de aula. É assim, desde a formação inicial do professor de Física que esta troca se dá, visto que existe a busca pela formação baseada no ensino, pesquisa e extensão e, nas trocas de experiências realizadas na escola; estabelecendo assim a relação universidade-escola (ALVES et al, 2010). Para Camargo (s/d) as práticas de ensino oferecem a oportunidade das primeiras experiências didáticas para os licenciados; isso promove reflexões na formação inicial desse acadêmico e deixa claro que ao final do curso o aluno deve continuar estudando, buscando novos conhecimentos, que a faculdade foi apenas o "pontapé" inicial para a carreira docente. 


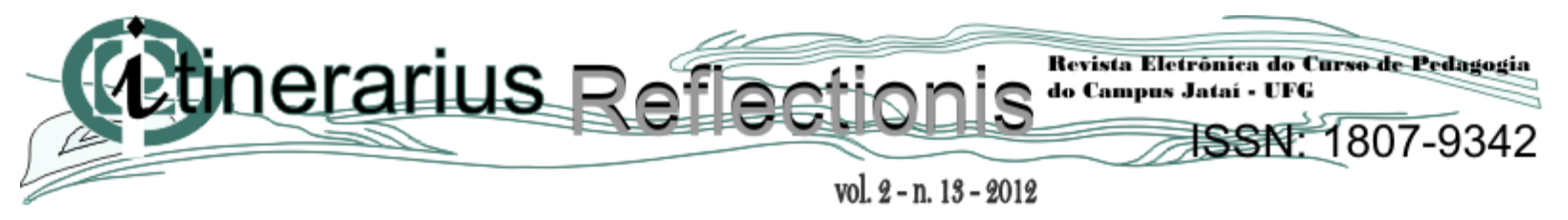

Nesse sentido espera-se que as instituições formadoras de professores de Física em Jataí estejam com seus estágios bem estruturados.

\subsection{Legislação}

Um professor de física durante a sua formação passa por vários temas, assuntos e problemas, mas como são definidos esses conteúdos, a matriz curricular do seu curso? Existe uma legislação específica para a sua formação, o que norteia a formação do currículo, a quantidade mínima de horas e de conteúdo a ser ministrado.

No relatório do Conselho Nacional de Educação, parecer n CNE/CES 1.304/2001 sobre as diretrizes nacionais curriculares para os cursos de Física, o Conselheiro faz as seguintes observações:

É praticamente consenso que a formação em Física, na sociedade contemporânea, deve se caracterizar pela flexibilidade do currículo de modo a oferecer alternativas aos egressos. É também bastante consensual que essa formação deve ter uma carga horária de cerca de 2400 horas distribuídas, normalmente, ao longo de quatro anos. Desse total, aproximadamente a metade deve corresponder a um núcleo básico comum e a outra metade a módulos sequenciais complementares definidores de ênfases. É igualmente consensual que, independentemente de ênfase, a formação em Física deve incluir uma monografia de fim de curso, a título de iniciação científica.

Nas Diretrizes Curriculares para os cursos de Física tem-se quais as competências e habilidades que um graduado em Física deve ter: descrever e explicar fenômenos naturais; utilizar a matemática como linguagem para a expressão dos fenômenos maturais; resolver problemas; dentre outros. Para a Licenciatura em Física as habilidades específicas incluem também o planejamento de experiências didáticas e elaboração ou adaptação de materiais didáticos (CNE/CES 1.304/2001)

A estrutura do curso deve ser dividida em duas partes: um núcleo comum (a todos os 


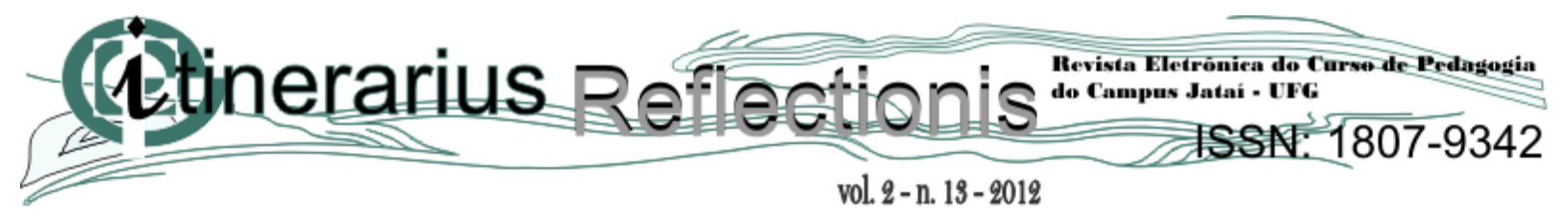

cursos de física) e um módulo sequencial (parte específica da formação). A carga horária é de aproximadamente $50 \%$ para o núcleo comum e 50\% para o módulo sequencial. No núcleo comum o conjunto das disciplinas é relativo à física geral, matemática, física clássica e moderna e a ciência como atividade humana. No módulo sequencial para a Licenciatura a ideia é o ensino da Física incluindo produção de material instrucional, conteúdos da educação básica e as Diretrizes Curriculares para educação básica, ensino médio e superior. Além dessa estrutura os cursos devem ter estágios e uma monografia como conclusão do curso (CNE/CES 1.304/2001).

Os cursos de licenciatura, em geral, são regulamentados pela Resolução $\mathrm{CNE} / \mathrm{CP}^{\circ}{ }^{\circ} 2$ que institui a duração e a carga horária dos cursos de licenciatura:

Art. $1^{\circ}$ A carga horária dos cursos de Formação de Professores da Educação Básica, em nível superior, em curso de licenciatura, de graduação plena, será efetivada mediante a integralização de, no mínimo, 2800 (duas mil e oitocentas) horas, nas quais a articulação teoria-prática garanta, nos termos dos seus projetos pedagógicos, as seguintes dimensões dos componentes comuns:

I - 400 (quatrocentas) horas de prática como componente curricular, vivenciadas ao longo do curso;

II - 400 (quatrocentas) horas de estágio curricular supervisionado a partir do início da segunda metade do curso;

III - 1800 (mil e oitocentas) horas de aulas para os conteúdos curriculares de natureza científico cultural ;

IV - 200 (duzentas) horas para outras formas de atividade acadêmicocientíficos-culturais.

Essa carga horária deve ser cumprida em 200 dias letivos como previsto na LDB $9.394 / 1996$.

1.2 Análise dos projetos pedagógicos dos cursos

Partindo do que a legislação instrui, analisamos as matrizes curriculares dos cursos de Licenciatura em Física do IFG/Campus Jataí e da UFG/Campus Jataí, comparando-as; assim esperamos que seja possível verificar se os cursos são similares. Primeiro analisou-se os projetos 


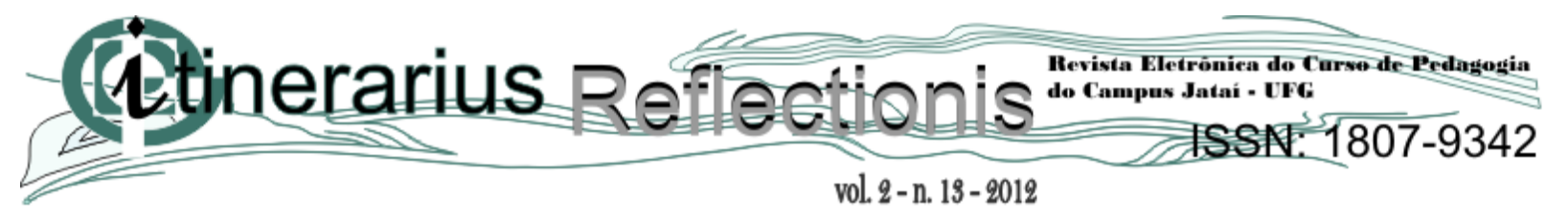

pedagógicos dos cursos (PPC) separados, observando se estão de acordo com a legislação; num segundo momento analisou-se as matrizes curriculares comparando as disciplinas, suas denominações, sua carga horária bem como as respectivas ementas e bibliografias.

\subsubsection{UFG/ Campus Jataí}

O curso de Licenciatura em Física da UFG-Campus Jataí tem duração de 4 anos (8 semestres), é noturno, abre 40 vagas anuais preenchidas conforme processo seletivo da UFG. No atual PPC do curso a carga horária total é de 2.952 horas, incluindo as 400 horas de estágio, 400 horas de prática de ensino e 200 horas de atividades complementares. Na primeira metade do curso o aluno recebe conhecimentos de Física Básica, Matemática, Computação, Química e Pedagogia; na segunda metade recebe conhecimentos mais avançados sobre Física, Práticas de Ensino e Estágio.

A atuação principal do licenciado em Física é a docência na Educação Básica, Tecnológica e Ensino Superior, mas pode atuar em outras áreas, dentre elas o ensino não formal, a pesquisa e setores da indústria. A ideia do curso de Física da UFG /Campus Jataí é formar profissionais com competência técnica e percepção crítica, que exige pessoas abertas à mudanças e à adaptações.

O que se espera da formação desse profissional está descrito no item 6: Expectativa da formação do profissional, no PPC. Ali é demonstrado o perfil do egresso, suas habilidades e competências, tudo baseado no que diz o parecer CNE /CES n 1304/2011, Com relação ao estágio e a prática como componente do currículo o PPC traz a legislação que regula (Parecer CNE/CP n²8/2001) e descreve as disciplinas que tratam desses assuntos, estágio I ao IV e quais os objetivos espera-se que os alunos desenvolvam.

A avaliação do curso de Física prevista no PPC acontece com a avaliação dos docentes feita pelos alunos, no desempenho dos mesmos no Exame Nacional de Desempenho dos Alunos (Enade); e também com a inserção dos alunos no mercado de trabalho. A avaliação da 


\section{Ctinerarius Refoctions \\ vol. 2 - n. $19-2012$

aprendizagem é parte importante do PPC, nela são apresentados mecanismos que os professores utilizam buscando explicitar simbolicamente o resultado do processo de aprendizagem.

A carga horária é distribuída entre núcleos básico, livre e atividades complementares, sendo 1.280 horas (46,5\% do total) para o núcleo comum; 1.312 horas (47,7\% do total) para o núcleo específico; 160 horas (5,8\% do total) para o núcleo livre, totalizando assim $100 \%$ da carga horária de disciplinas, 2.752 horas. Além de 200 horas para atividades complementares, perfazendo 2.952 horas, a carga horária total do curso.

\subsubsection{IFG/ Campus Jataí}

O curso tem duração de 4 anos (8 semestres), é noturno, com entrada semestral. Oferta-se 30 vagas por semestre totalizando 60 vagas no ano. No PPC em vigência no ano de 2012 o curso tem a carga horária total de 3.117 horas, incluindo 200 horas de atividades complementares, 200 horas de TCC (trabalho de conclusão de curso), 400 horas de prática de ensino e 400 horas de estágio.

O curso de Licenciatura em Física do IFG/Câmpus Jataí forma educadores em Física com perfil para atuação no ensino médio, devido à demanda de professores dessa área na região de Jataí. Oferece para seus licenciandos condições necessárias para o magistério, com conteúdos específicos de Física e também conteúdos e habilidades de cunho educativo/pedagógico, tanto teórico como prático.

O perfil esperado do profissional formado no IFG/Campus Jataí é:

[...] um profissional com conhecimentos sólidos e atualizados, dedicando-se a construção desses conhecimentos e do saber científico junto ao educando, no ensino médio ou em outras modalidades de ensino.

No decorrer do PPC apresenta-se o suporte legal para a criação e manutenção do curso. Além de como funciona o estágio e o trabalho de conclusão do curso, as atividades 


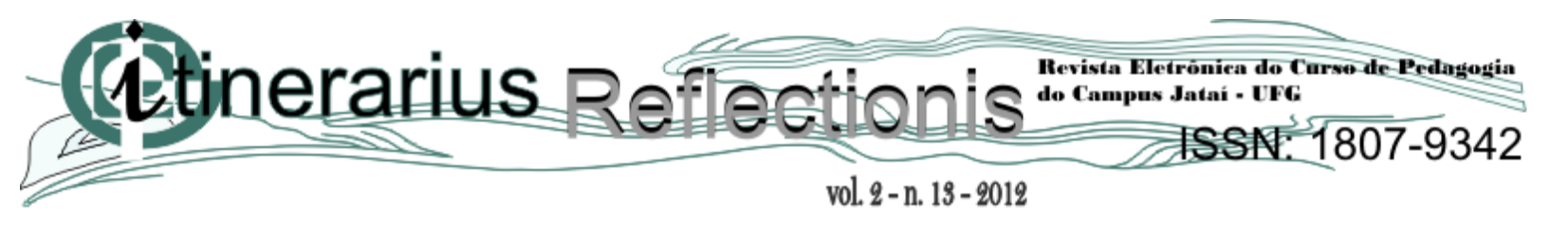

complementares e as práticas de ensino. Tudo baseado na lei e nos pareceres do Conselho Nacional de Educação. Com relação a avaliação da aprendizagem é dito o seguinte:

Os alunos serão avaliados conforme determina a Organização Didática do IF-GO, observando-se a necessidade da contínua busca de novas formas de avaliação, as quais deverão ser discutidas com os professores e alunos do curso. Tendo em vista que esses alunos serão futuros professores e deverão, desde já, estar aptos para discutir e avaliar formas de avaliações, essa discussão do processo de avaliação e a busca de novas formas de avaliação são muito importantes para sua formação.

A carga horária no IFG/Campus Jataí é distribuída da seguinte forma: núcleo pedagógico, núcleo específico e núcleo complementar. O núcleo específico é formado por disciplinas voltadas para a formação em Física, sendo composto por disciplinas de Física, Matemática e disciplinas complementares que ampliem a educação do graduando. O núcleo pedagógico é formado por disciplinas relativas à prática educativa escolar, as chamadas “disciplinas pedagógicas". Sendo 1.351 horas (43,34\% do total) para o núcleo pedagógico; 1.431 horas $(45,91 \%$ do total) para o núcleo específico; 335 horas (10,75\% do total) para o núcleo complementar, totalizando assim 3.117 horas, $100 \%$ da carga horária do curso.

\subsubsection{Matrizes Curriculares}

Nas matrizes curriculares distribui-se o fluxo das disciplinas, as disciplinas por período e quais são os pré-requisitos. A matriz curricular traz além do fluxo de disciplinas, o ementário das mesmas com as suas bibliografias básicas e bibliografias complementares. A partir disso serão comparadas as matrizes do IFG e da UFG.

O Quadro 01 expõe as disciplinas do núcleo referentes à formação específica em Física. 


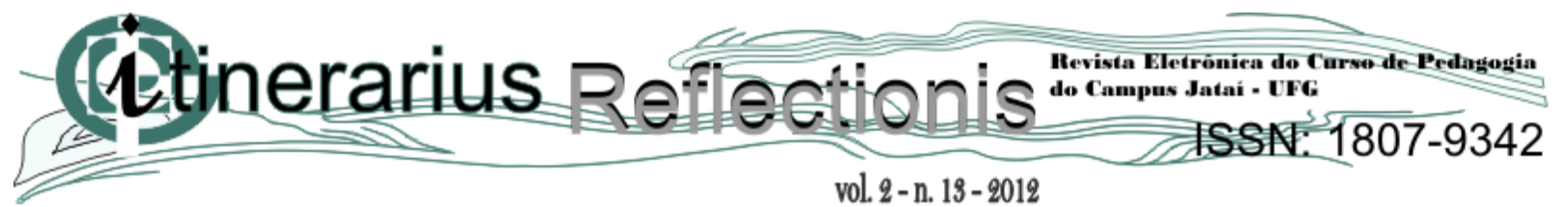

Quadro 01: Disciplinas da Formação Específica em Física

\begin{tabular}{|c|c|c|c|c|c|}
\hline \multicolumn{3}{|l|}{ IFG } & \multicolumn{3}{|c|}{ UFG } \\
\hline Disciplinas & Carga & Período & Disciplinas & Carga & Período \\
\hline Cálculo Diferencial & 81 & $1^{\circ}$ & Cál. e Geometria Analítica I & 64 & $2^{\circ}$ \\
\hline Geometria Analítica & 54 & $1^{\circ}$ & Cál. e Geometria Analítica II & 64 & $3^{\circ}$ \\
\hline Cálculo Integral & 54 & $2^{\circ}$ & Cál. e Geometria Analítica III & 96 & $4^{\circ}$ \\
\hline Cál. das fun. de várias variáveis I & 54 & $3^{\circ}$ & Princípios de Álgebra e Cálculo & 96 & $1^{\circ}$ \\
\hline Cál. das fun. de várias variáveis II & 54 & $4^{\circ}$ & & & \\
\hline Química Geral & 54 & $2^{\circ}$ & Química Geral & 64 & $2^{\circ}$ \\
\hline História da Ciência & 54 & $7^{\circ}$ & Introdução a Física & 32 & $1^{\circ}$ \\
\hline Astronomia & 54 & $6^{\circ}$ & Evolução da Física I & 32 & $1^{\circ}$ \\
\hline Ciência Ambiental & 54 & $6^{\circ}$ & Evolução da Física II & 32 & $8^{\circ}$ \\
\hline Mecânica I & 81 & $2^{\circ}$ & Mecânica Clássica & 64 & $7^{\circ}$ \\
\hline Mecânica II & 81 & $3^{\circ}$ & & & \\
\hline Eletricidade e Magnetismo & 54 & $4^{\circ}$ & Teoria Eletromagnética & 64 & $6^{\circ}$ \\
\hline Eletromagnetismo & 54 & $5^{\circ}$ & & & \\
\hline Física Moderna & 81 & $7^{\circ}$ & Física Moderna & 96 & $6^{\circ}$ \\
\hline Física Térmica & 54 & $4^{\circ}$ & Física I & 96 & $2^{\circ}$ \\
\hline Oficina de Ensino de Física I & 54 & $5^{\circ}$ & Física II & 96 & $3^{\circ}$ \\
\hline Oficina de Ensino de Física II & 54 & $6^{\circ}$ & Física III & 96 & $4^{\circ}$ \\
\hline Lab. de Física Ond. E Óptica & 27 & $5^{\circ}$ & Física IV & 64 & $5 /$ \\
\hline Laboratório de Física Básica & 81 & $1^{\circ}$ & Laboratório de Física I & 32 & $2^{\circ}$ \\
\hline Laboratório de Mecânica I & 27 & $2^{\circ}$ & Laboratório de Física II & 32 & $3^{\circ}$ \\
\hline Laboratório de Mecânica II & 27 & $3^{\circ}$ & Laboratório de Física III & 32 & $4^{\circ}$ \\
\hline Lab. Eletricidade e Magnetismo & 27 & $4^{\circ}$ & Laboratório de Física IV & 32 & $5^{\circ}$ \\
\hline Laboratório de Física Moderna & 27 & $7^{\circ}$ & Laboratório de Física Moderna & 32 & $7^{\circ}$ \\
\hline Física Ondulatória e Óptica & 54 & $5^{\circ}$ & Introdução a Computação & 64 & $4^{\circ}$ \\
\hline Estrutura da Matéria & 81 & $8^{\circ}$ & & & \\
\hline Tóp. de Fís. Nuclear E de Partículas & 54 & $8^{\circ}$ & & & \\
\hline Total & 1.431 & & Total & 1.280 & \\
\hline
\end{tabular}

O Quadro 02 apresenta disciplinas do núcleo pedagógico específicas para a formação

do professor.

Quadro 02: Disciplinas de Formação Pedagógica

\begin{tabular}{|l|l|l|l|l|l|l|}
\hline \multicolumn{2}{|c|}{ IFG UFG } & \multicolumn{2}{c|}{ Carga } & Período \\
\hline Disciplina & Carga & Período & Disciplina & 64 & $1^{\circ}$ \\
\hline Fund. Sócio Filosóficos da Educação & 54 & $1^{\circ}$ & Fund. Sócio Filosóficos da Educação & 64 & $1^{\circ}$ \\
\hline Psicologia da Educação & 54 & $3^{\circ}$ & Psicologia da Educação I & 64 & $2^{\circ}$ \\
\hline & & & Psicologia da Educação II & 64 & 64 & $3^{\circ}$ \\
\hline Didática da Física & 54 & $4^{\circ}$ & Didática para o Ensino de Física & 64 & $3^{\circ}$ \\
\hline Políticas e Gestão da Edu. Básica & 54 & $5^{\circ}$ & Políticas Educacionais no Brasil & 96 & $5^{\circ}$ \\
\hline Estágio I & 54 & $6^{\circ}$ & Estágio I & 96 & $6^{\circ}$ \\
\hline Estágio II & 81 & $7^{\circ}$ & Estágio II & 96 & $7^{\circ}$ \\
\hline Estágio III & 108 & $8^{\circ}$ & Estágio III & & 112 & $8^{\circ}$ \\
\hline Complementação do Estágio & 157 & & Estágio IV & & & \\
\hline
\end{tabular}




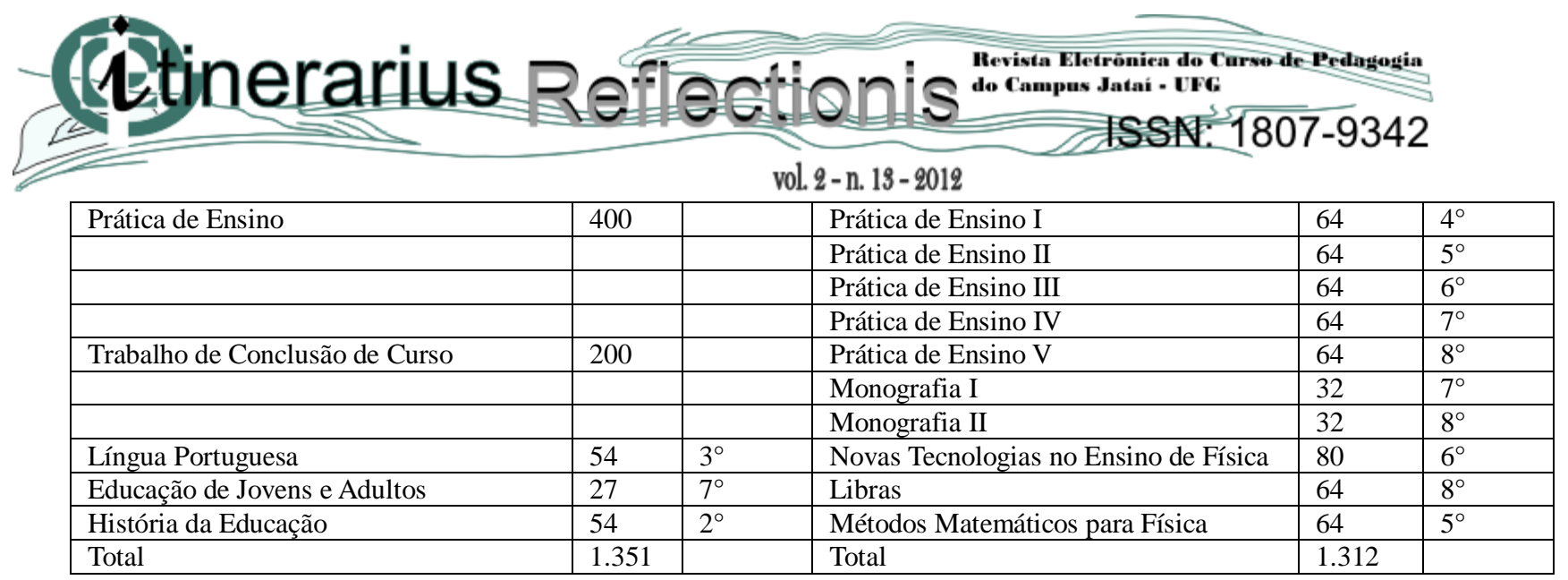

No IFG algumas disciplinas são consideradas núcleo comum, são 135 horas divididas entre quatro disciplinas; são elas Língua Portuguesa, Letras-Libras I e II e Relações Étnico Raciais e Cultura Afro-Brasileira e Indígena. Além dessas horas existem 200 horas de atividades complementares, o que também acontece na UFG; esta possui 160 horas de núcleo livre, que são distribuídas em disciplinas de escolha dos alunos. Nos quadros acima a ideia é comparar os núcleos pedagógicos e de formação em Física. Observa-se que no IFG algumas atividades pedagógicas não são disciplinas propriamente ditas, são atividades desenvolvidas durante toda a graduação ou a partir de determinado período previsto no PPC da instituição; sendo estas atividades o TCC, a Prática de Ensino - praticada ao longo do ano - e uma complementação de estágio.

\subsubsection{Disciplinas com a mesma denominação}

A seguir são apresentadas para análise disciplinas que possuem nomes iguais nas duas instituições.

As disciplinas foram escolhidas para a comparação por possuírem o mesmo nome para verificar se as ementas eram iguais ou parecidas e o conteúdo aplicado era correspondente ou se havia diferença no conteúdo.

\section{a) Física Moderna}




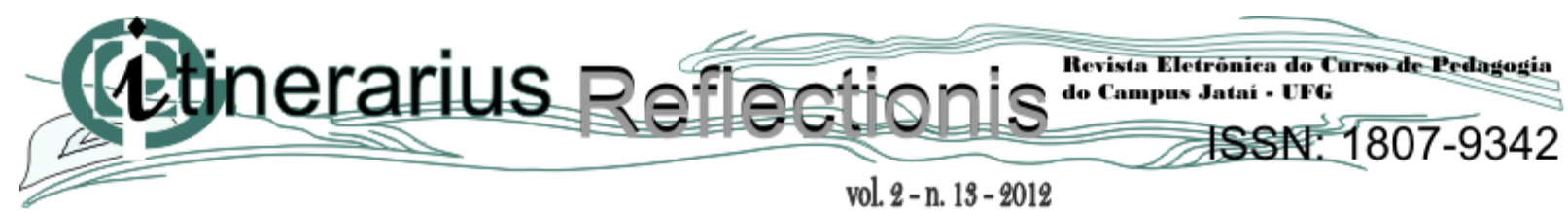

A ementa da UFG/Campus Jataí:

Teoria da relatividade; radiação térmica e origens da mecânica quântica; dualidade onda-partícula; bases químicas da teoria atômica; átomo de Bohr; equação de Schrödinger; Aplicações da equação de Schrödinger; átomos de um elétron; spin e momentos de dipolo magnético; átomos de muitos elétrons; modelos nucleares; decaimento e reações nucleares; partículas elementares.

A ementa do IFG/Campus Jataí:

Relatividade Especial. Propriedades Corpusculares da Radiação. Radiação Térmica e o Postulado de Planck. Dualidade onda-partícula. Propriedades ondulatórias das partículas e o postulado de De Broglie. Princípio da Incerteza de Heisenberg. Equação de Schrödinger. Aplicações da equação de Schrödinger.

Como é possível observar a ementa do curso de Física da UFG/Campus Jataí descreve mais os conteúdos que serão aplicados aos alunos da disciplina; já a ementa do IFG/Campus Jataí é mais sucinta, mais geral. Pelo conteúdo descrito no IFG a disciplina de Física Moderna tem menos conteúdo a ser aplicado, porém sua carga horária é menor. No IFG a disciplina é ofertada no $7^{\circ}$ período com uma carga horária de 81 horas, já na UFG é ofertada no $6^{\circ}$ período com uma carga horária de 96 horas.

b) Laboratório de Física Moderna

A ementa da UFG/Campus Jataí traz: "Experiências em física moderna e clássica envolvendo conceitos de física nuclear, estrutura atômica da matéria, física do estado sólido e óptica".

A ementa do IFG/Campus Jataí traz: "Experimentos e simulações envolvendo conceitos de Física Moderna".

A ementa da UFG/Campus Jataí é mais explicativa, enquanto a do IFG/Campus Jataí 


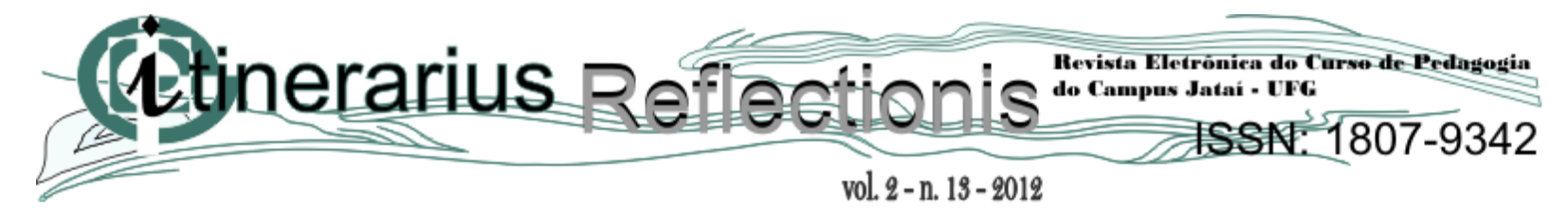

é objetiva, porém caracteriza o que será apresentado nessa disciplina, às duas ementas deixam explicito o que será ensinado. No IFG a disciplina é ofertada no $7^{\circ}$ período com uma carga horária de 27 horas; já na UFG é ofertada também no $7^{\circ}$ período com carga horária de 32 horas.

c) Química Geral

Na ementa da UFG/Campus Jataí tem-se:

A matéria e seus estados físicos; transformações da matéria: reações químicas; mol e estequiometria das reações; termoquímica e espontaneidade das reações; equilíbrio químico: ácido-base e eletroquímico; propriedades das soluções: unidades de concentração e propriedades coligativas; modelos atômicos de Bohr e orbital; periodicidade química; ligação química: geometria molecular e teorias de ligação. Introdução aos procedimentos de segurança no manuseio e descarte de produtos e resíduos.

Na ementa do IFG/Campus Jataí tem-se:

Modelos de constituição da matéria, tabela periódica, conceito de mol, ligações químicas, compostos moleculares e iônicos, forças intermoleculares, eletroquímica, química nuclear.

Em nossa análise a ementa do IFG/Campus Jataí é um pouco mais clara, porém menos explicativa do que a ementa da UFG/Campus Jataí, que traz mais detalhes do que os alunos da disciplina Química Geral irão aprender. A disciplina é ofertada no IFG no $2^{\circ}$ período com carga horária de 54 horas e na UFG é ofertada também no $2^{\circ}$ período com carga horária de 64 horas.

d) Psicologia da Educação

A ementa da UFG/Campus Jataí

Psicologia da Educação I: Introdução ao estudo da Psicologia: fundamentos históricos e epistemológicos; a relação Psicologia e Educação. Abordagens 


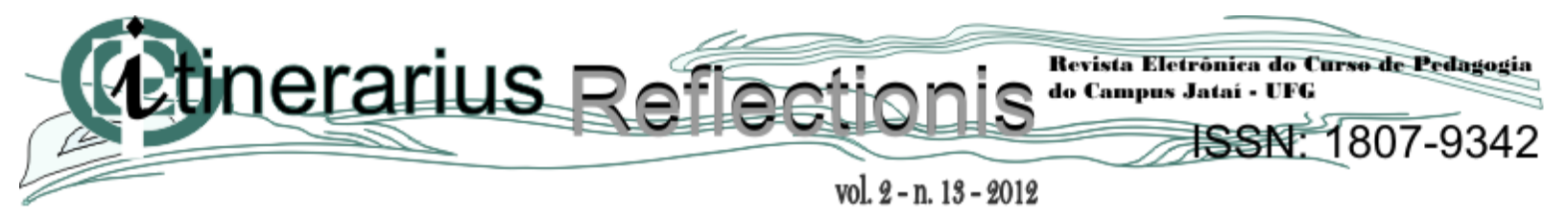

teóricas: comportamental e psicanalítica e suas contribuições para a compreensão do desenvolvimento cognitivo, afetivo, social e psicomotor e suas implicações no processo ensino-aprendizagem.

Psicologia da Educação II: Abordagens teóricas: psicologia genética de Piaget, psicologia sócio-histórica de Vygotsky e suas contribuições para a compreensão do desenvolvimento cognitivo, afetivo, social e psicomotor e suas implicações no processo ensino-aprendizagem.

A ementa do IFG/Campus Jataí:

Introdução ao estudo da Psicologia como ciência: seu objeto de estudo. Relação entre Psicologia e Pedagogia. Desenvolvimento (psicomotor, emocional, cognitivo e social) e o papel do professor nas situações de ensino e aprendizagem: atitude e procedimento. O comportamento do indivíduo no grupo. Os processos de grupo na instituição escolar. Teorias interacionistas: Interacionismo de Jean Piaget, Interacionismo sóciohistórico de Vygotsky, Interacionismo em Wallon implicações pedagógicas, Teorias humanistas e fenomenológicas (Rogers e Jung). Teoria da aprendizagem significativa. A aprendizagem de jovens, adolescentes e adultos. A Psicologia e o trabalho docente. Dificuldades da aprendizagem.

A disciplina Psicologia da Educação é ofertada no IFG/Campus Jataí somente no $3^{\circ}$ período do curso com carga horária de 54 horas. Na UFG/Campus Jataí a disciplina é ofertada em dois períodos sendo dividida em Psicologia da Educação I e II, $1^{\circ}$ e $2^{\circ}$ períodos respectivamente, sendo cada uma delas com carga horária de 64 horas. As ementas são semelhantes, porém a do IFG é mais detalhada. Aqui temos uma diferença de carga horária interessante, enquanto o IFG oferece a disciplina com 54 horas a UFG dispõe de 128 horas para trabalhar o mesmo conteúdo, a princípio os alunos da UFG terão mais contato com o assunto, e teoricamente desenvolverão melhor as habilidades previstas na ementa da disciplina.

e) Libras

A ementa da UFG/Campus Jataí:

Introdução à Língua Brasileira de Sinais - LIBRAS. Apresentação de conteúdos 


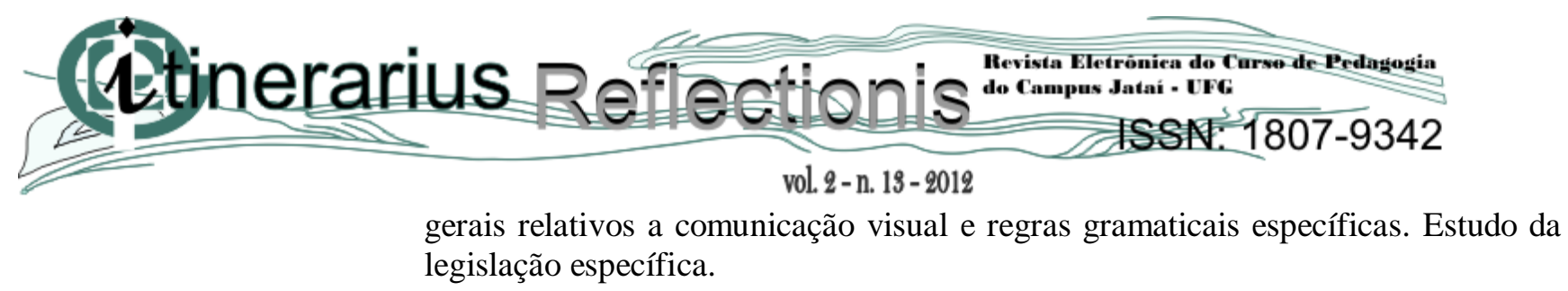

A ementa do IFG/Campus Jataí:

LETRAS-LIBRAS I: Conceituação e caracterização da Língua Brasileira de Sinais - LIBRAS como forma de comunicação e expressão do surdo. Estudos dos pressupostos teóricos-históricos, filosóficos, sociológicos, pedagógicos e técnicos da Língua Brasileira de Sinais - LIBRAS na comunicação entre o professor e o aluno surdo. A prática de Libras: a expressão visual-espacial para a sociedade e para o ensino da Física.

LETRAS-LIBRAS II: Conceituação e caracterização da Língua Brasileira de Sinais - LIBRAS como forma de comunicação e expressão do surdo. Estudos dos pressupostos teóricos-históricos, filosóficos, sociológicos, pedagógicos e técnicos da Língua Brasileira de Sinais - LIBRAS na comunicação entre o professor e o aluno surdo. A legislação vigente a respeito da Língua Brasileira de Sinais LIBRAS e dos direitos da pessoa surda. A prática de Libras: a expressão visualespacial para a sociedade e para o ensino da Física.

A disciplina de Libras é ofertada no curso de Física da UFG/Campus Jataí no $8^{\circ}$ período com carga horária de 64 horas, já no IFG/Campus Jataí ela é ofertada em dois semestres, sendo Letras-Libras I e II, $4^{\circ}$ e $5^{\circ}$ períodos respectivamente com carga horária de 27 horas cada uma. A ementa da UFG é reduzida, bem objetiva; já a do IFG é bem explicativa, demonstra o que será apresentado para os alunos, o que eles desenvolverão em sala de aula, mas de uma disciplina para outra só acrescenta a legislação vigente, ou seja, eles terão praticamente a mesma coisa de um semestre para outro.

Após apresentar as disciplinas de mesmo nome e descrever suas ementas, é possível fazer algumas considerações. As ementas são apresentadas de forma curta e pouco explicativas em alguns casos, em outros é mais extensa trazendo mais conteúdos (ou detalhando mais os conteúdos); mesmo assim elas não são fechadas, assim o professor tem certa liberdade na hora das aulas, já que os laboratórios e as bibliotecas não são suficientes para proporcionar ao professor material didático suficiente para ministrar suas aulas, pode haver improvisos. 


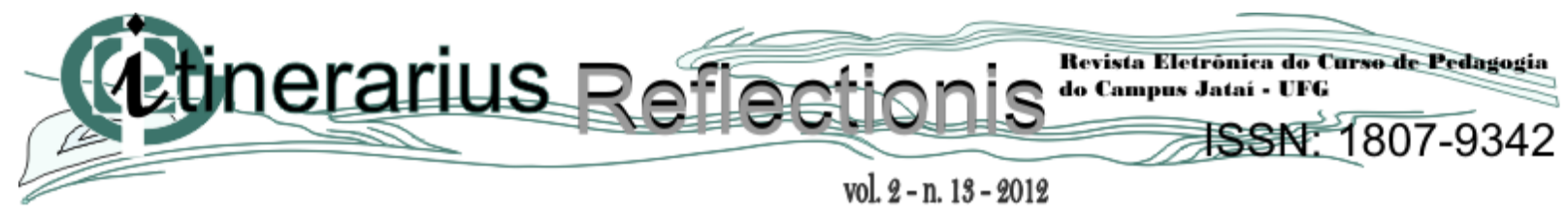

Outras disciplinas têm nomes e ementas semelhantes. Graças à legislação que regula os cursos de formação de professores de Física; as ementas, os nomes das disciplinas e as cargas horárias delas são semelhantes entre si, assim não existe uma discrepância muito grande entre as instituições. Para que algumas disciplinas sejam cursadas é necessário a aprovação em disciplina pré-requisito, algo comum nas instituições.

Ao observar a matriz curricular das unidades escolares é possível afirmar que elas estão de acordo com a legislação vigente, aplicando aproximadamente 50\% da carga horária para o núcleo de formação em Física e o restante na parte pedagógica.

\section{Considerações finais}

Após analisar os PPC dos cursos de Física ofertados na cidade de Jataí, pode-se concluir que os cursos estão bem próximos quanto ao conteúdo que o graduando irá aprender durante sua graduação porque a legislação exige isso. Na UFG temos um ementário mais claro e detalhado em algumas disciplinas e em outras inverte, como é o caso das disciplinas Química Geral e Libras. A carga horária total do curso do IFG é de 3.117 horas enquanto que a da UFG é de 2.952 horas.

Os cursos, nas duas instituições possuem 400 horas dedicadas ao estágio dos alunos e 200 horas de atividades complementares; no IFG a prática de ensino é de 400 horas enquanto na UFG é de 320 horas, a legislação vigente Resolução CNE/CP n 2 traz que são necessária 400 horas de prática de ensino, aqui há uma diferença em relação a legislação por parte da UFG, o restante está em conformidade com a Lei. Quanto ao Trabalho Final de Curso (TCC) na UFG são ofertadas as disciplinas de monografia I e II, que ocorrem nos $7^{\circ}$ e $8^{\circ}$ períodos, totalizando 64 horas; já no IFG o TCC corresponde a 200 horas, oferecido aos alunos fora do fluxo das disciplinas podendo ser desenvolvido a partir do $7^{\circ}$ período desde que o aluno tenha completado de modo satisfatório metade do curso, ou seja, não pode dever nenhuma disciplina dos dois 


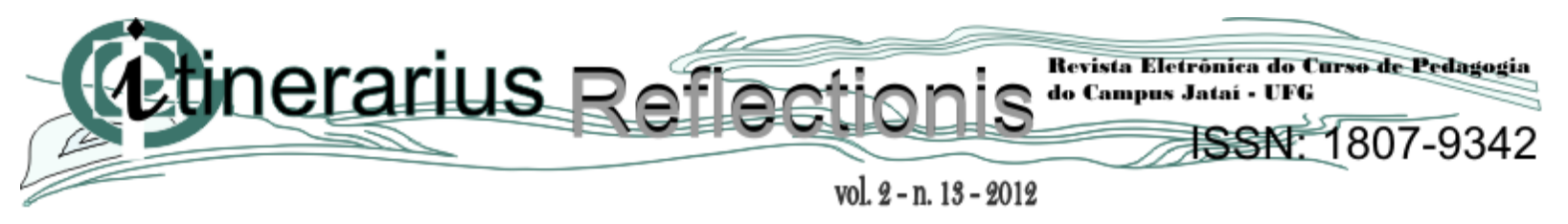

primeiros anos escolares. Acredita-se que a UFG consegue ser mais eficaz, visto que o trabalho é executado dentro do fluxo de disciplinas e uma depende da outra, o aluno só termina a graduação fechando todas as matérias; no caso do IFG não existe a obrigatoriedade do início no último ano de curso, o aluno pode optar por concluir todas as disciplinas e depois fazer o TCC, o que causa um atraso na formatura desses graduandos.

Outra questão que fica evidente no PPC é o objetivo do curso de física para cada instituição, no caso do IFG o objetivo é a formação de professores para o Ensino Médio e depois para outros níveis escolares, como visto a seguir:

[...] objetivo principal a formação de educadores em Física com perfil para atuação no ensino de nível médio, em face da demanda de professores de Física para o ensino médio na região de Jataí. O curso tem como meta oferecer aos seus graduandos as condições necessárias para o magistério, tanto do ponto de vista dos conteúdos específicos da física enquanto ciência, como também dos conteúdos e habilidades de cunho educativo/pedagógico, tanto no âmbito teórico quanto experimental (IFG, PPC, p. 24).

Na UFG o objetivo é uma sólida formação em Física, com enfoque na formação pedagógica, podendo assim o aluno formado exercer a profissão docente ou seguir em outras áreas da Física como visto a seguir:

O licenciado em Física tem como campo de atuação principal a docência na Educação Básica, Tecnológica e Ensino Superior, podendo estender seu campo profissional a outras áreas de atuação, como por exemplo, no ensino não formal, na pesquisa em Física ou Ensino de Física, no setor financeiro, na indústria etc. (UFG, PPC, p. 6)

Respondendo as indagações iniciais sobre a formação docente nas duas instituições partiu-se da análise da carga horária pedagógica, nos dados constantes nos PPC tem-se na UFG 1.312 horas enquanto que no IFG são 1.351 horas. Portanto a UFG/Campus Jataí tem menos horas dedicadas a formação do professor e não confere as especulações da comunidade ao dizer que a UFG forma bacharéis disfarçados de professores, visto que a diferença é mínima. Na carga 


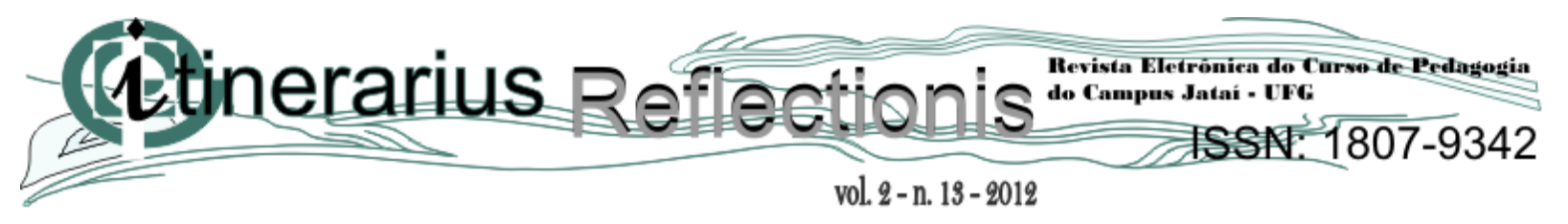

horária dedicada ao estudo da Física a UFG dispõe de 1.280 horas e o IFG 1.431 horas, novamente as especulações da comunidade não procedem, pois o IFG/Campus Jataí dispõe de mais horas dedicadas ao ensino de Física do que a UFG e nem assim o IFG forma bacharéis disfarçados.

$\mathrm{O}$ artigo ao analisar os PPC e suas matrizes conclui que as duas instituições possuem semelhanças em suas matrizes, que formam professores e não bacharéis, visto que a carga horária dedicada a parte pedagógica é muito próxima entre si e está em conformidade com a legislação. Com o visto e analisado nos PPC as instituições estão de acordo com a legislação e formam bem os profissionais da educação em nossa região.

\section{REFERÊNCIAS}

ALVES, João Amadeus Pereira; CARVALHO, Washington Luiz Pacheco de; MION, Rejane Aurora. A construção da identidade de professor e pesquisador em ensino de Física: um estudo de caso de uma proposta educacional desenvolvida na formação inicial de professores. Disponível em: <http://www.senept.cefetmg.br/permalink/32fe904c-77d4-11df-9034-001e4f1ef15c.html > Acesso em 20 nov. 2011.

BARDIN, L. Análise do conteúdo. Lisboa, Portugal: Edições Setenta, 1977.

BARONE, Paulo M. V. B.. Formação de professores de Física e de Ciências. In: Anais da Reunião anual da SBPC, 60., 2008, Campinas. Anais eletrônicos. São Paulo : SBPC/UNICAMP, 2008. Disponível em: <http://www.sbpcnet.org.br/livro/60ra/textos/MRPauloBarone.pdf >. Acesso em 20/11/2011.

BRASIL. CNE Parecer $n^{\circ}$ CNE/CES 1.304, de 06 de novembro 2001. Estabelece as Diretrizes Nacionais Curriculares para os Cursos de Física.

BRASIL. CNE. Resolução CNE/CP n 2, de 19 de fevereiro de 2002. Institui a duração e a carga horária dos cursos de licenciatura, de graduação plena, de formação de professores da Educação Básica em nível superior. 


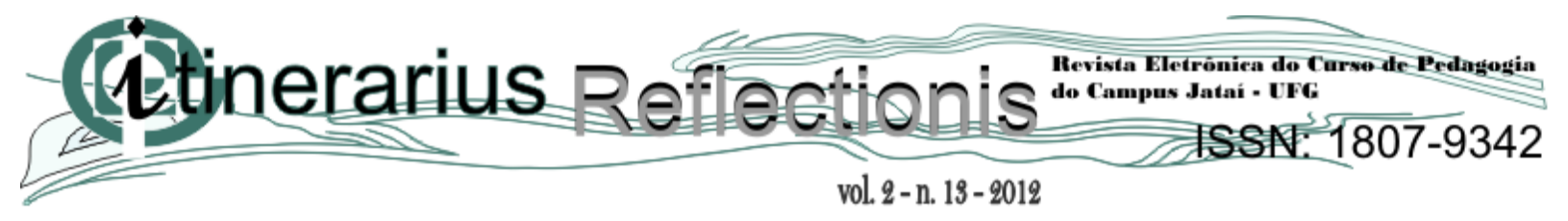

BRASIL. LDB Lei n 4.024, de 20 de dezembro de 1961. Fixa as Diretrizes e Bases da Educação Nacional.

Lei $n^{\circ} 5.540$, de 28 de dezembro de 1968. Fixa normas de organização e funcionamento do ensino superior e sua articulação com a escola média, e dá outras providências.

Lei $\mathrm{n}^{\circ} 5.692$, de 11 de agosto de 1971. Fixa Diretrizes e Bases para o ensino de $1^{\circ}$ e $2^{\circ}$ graus, e dá outras providências. nacional.

Lei no 9.394, de 20 de dezembro de 1996. Estabelece as Diretrizes e Bases da educação

BORGES, Oto. Formação inicial de professores de Física: Formar mais! Formar melhor! Revista Brasileira de Ensino de Física. v. 28, n.2, p. 135-142, abril. 2001.

CAMARGO, Sérgio; NARDI, Roberto. Formação de professores de Física: os estágios supervisionados como fonte de pesquisa sobre prática de ensino. s/d. Disponível em: <www.fae.ufmg.br/abrapec/revistas/V3N3/v3n3a3.pdf> . Acesso em 20/11/2011.

FERREIRA, Carlos Daniel de Oliveira; PEREIRA, Claudyane Bizerra; BREVES FILHO, José de Souza. Qual é o perfil do professor dos cursos de licenciatura do IFCE? Belém, 2009. Disponível em: http://connepi2009.ifpa.edu.br/connepi-anais/iniciar.htm\#\#. Acesso em: 08/mar./2011.

IFG/Câmpus Jataí. Projeto Pedagógico do Curso de Licenciatura em Física. Jataí (GO). Outubro de 2007 (última alteração 2011).

LEITE, Carlinda. Entre velhos desafios e novos compromissos, que currículo para a formação de professores? Anais do XIII ENDIPE - Novas subjetividades, currículo, docência e questões pedagógicas na perspectiva da inclusão social. p 277-298. Recife 2006.

MACHADO, Camila Correia; CAMARGO, Sérgio. Uma breve revisão histórica sobre a formação de professores de Física. Anais do IX Congresso Nacional de Educação EDUCERE / III Encontro Sul Brasileiro de psicopedagogia. PucPR, out. 2009.

MION, Rejane Aurora; SUTIL, Noemi. Formação de professores de Física, teoria crítica e a relação teoria-prática na elaboração de propostas educacionais. Disponível em <http://www.senept.cefetmg.br/galerias/Arquivos_senept/anais/terca_tema3/TerxaTema3Artigo1 


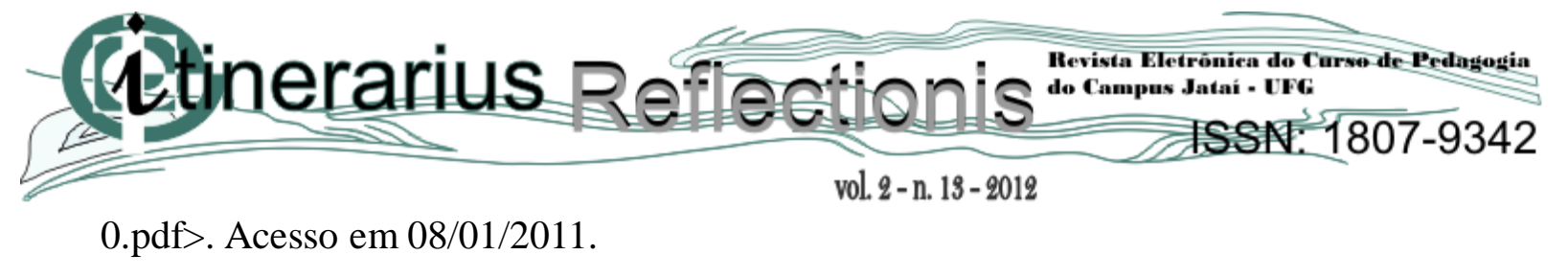

PEREIRA, Júlio Emílio Diniz. As licenciaturas e as novas políticas educacionais para a formação docente. Educação e Sociedade. Ano XX, n. 68. dez. 1999.

QUEIROZ, Glória Regina Pessôa Campello. Processos de formação de professores artistas reflexivos de Física. Educação e Sociedade. Ano XXII, n. 74. abril. 2001.

SANTANA, Adam David de Oliveira; CAVALHEIRO, Ademir; CARDOSO, Dayane Carvalho; MENDES, Elise Barbosa; SILVA, Franciscarlos Gomes da. Contribuição à formação do professor de Física no Ensino Médio e à sua prática pedagógica. XVI Simpósio Nacional de Ensino de Física.

Disponível

em:

<http://www.sbf1.sbfisica.org.br/eventos/snef/xvi/cd/listatrabarea_02.html> Acesso em 20/11/2011,

SÁ-SILVA, J.R. et al. Pesquisa documental: pistas teóricas e metodológicas. Disponível em $<$ http://www.rbhcs.com/index_arquivos/Artigo. Pesquisa\%20documental.pdf $>$. Acesso em 30/09/2010.

SCHEIBE, Leda. Formação de professores no Brasil - A herança histórica. Revista Retratos da Escola, Brasília, v. 2, n. 2-3, p. 41-53, jan./dez. 2008.

TRICÁRICO, Hugo Roberto. A formação dos professores de Física. Cad. Cat. Ens. Fís., Florianópolis, 6(2):143-147, ago. 1989.

UFG/Câmpus Jataí. Projeto Pedagógico do Curso de Licenciatura em Física. Jataí (GO). Dezembro de 2007 (última alteração - outubro de 2010). 